\title{
Interactions of $17 \beta$-Hydroxysteroid Dehydrogenase Type 10 and Cyclophilin D in Alzheimer's Disease
}

\author{
Zdenka Kristofikova $^{1}$ (1) - Tomas Springer ${ }^{2} \cdot$ Erika Gedeonova $^{2} \cdot$ Adéla Hofmannova $^{1} \cdot$ Jan Ricny ${ }^{1}$. \\ Lenka Hromadkova ${ }^{1} \cdot$ Martin Vyhnalek $^{3}$. Jan Laczo ${ }^{3}$. Tomas Nikolai ${ }^{3}$. Jakub Hort ${ }^{3}$. Tomas Petrasek ${ }^{1,4}$. \\ Ales Stuchlik ${ }^{4} \cdot$ Karel Vales $^{1} \cdot$ Jan Klaschka ${ }^{5} \cdot$ Jiri Homola ${ }^{2}$
}

Received: 28 August 2019 / Revised: 14 January 2020 / Accepted: 20 January 2020 / Published online: 29 January 2020

(c) The Author(s) 2020

\begin{abstract}
The nucleus-encoded 17 $\beta$-hydroxysteroid dehydrogenase type 10 (17 $\beta$-HSD10) regulates cyclophilin D (cypD) in the mitochondrial matrix. CypD regulates opening of mitochondrial permeability transition pores. Both mechanisms may be affected by amyloid $\beta$ peptides accumulated in mitochondria in Alzheimer's disease (AD). In order to clarify changes occurring in brain mitochondria, we evaluated interactions of both mitochondrial proteins in vitro (by surface plasmon resonance biosensor) and detected levels of various complexes of 17ß-HSD10 formed in vivo (by sandwich ELISA) in brain mitochondria isolated from the transgenic animal model of AD (homozygous McGill-R-Thy1-APP rats) and in cerebrospinal fluid samples of $\mathrm{AD}$ patients. By surface plasmon resonance biosensor, we observed the interaction of $17 \beta$-HSD10 and cypD in a direct real-time manner and determined, for the first time, the kinetic parameters of the interaction $\left(k_{a} 2.0 \times 10^{5} \mathrm{M}^{1} \mathrm{~s}^{-1}, k_{d} 5.8 \times 10^{4}\right.$ $\mathrm{s}^{-1}$, and $\left.K_{D} 3.5 \times 10^{-10} \mathrm{M}\right)$. In McGill-R-Thy 1-APP rats compared to controls, levels of 17 $\beta$-HSD10-cypD complexes were decreased and those of total amyloid $\beta$ increased. Moreover, the levels of 17 $\beta$-HSD10-cypD complexes were decreased in cerebrospinal fluid of individuals with AD (in mild cognitive impairment as well as dementia stages) or with Frontotemporal lobar degeneration (FTLD) compared to cognitively normal controls (the sensitivity of the complexes to AD dementia was $92.9 \%$, that to FTLD $73.8 \%$, the specificity to AD dementia equaled $91.7 \%$ in a comparison with the controls but only $26.2 \%$ with FTLD). Our results demonstrate the weakened ability of $17 \beta$-HSD10 to regulate cypD in the mitochondrial matrix probably via direct effects of amyloid $\beta$. Levels of 17 $\beta$-HSD10-cypD complexes in cerebrospinal fluid seem to be the very sensitive indicator of mitochondrial dysfunction observed in neurodegeneration but unfortunately not specific to AD pathology. We do not recommend it as the new biomarker of AD.
\end{abstract}

Keywords Mitochondrial matrix proteins $\cdot$ Amyloid $\beta \cdot$ Transgenic rat model $\cdot$ Alzheimer's disease $\cdot$ Frontotemporal lobar degeneration $\cdot$ Cerebrospinal fluid

Zdenka Kristofikova

zdenka.kristofikova@nudz.cz

1 National Institute of Mental Health, Topolova 748, 25067 Klecany, Czech Republic

2 Institute of Photonics and Electronics of the Czech Academy of Sciences, Chaberska 57, 18251 Prague, Czech Republic

3 Department of Neurology, Memory Disorders Clinic, 2nd Faculty of Medicine, Charles University in Prague and Motol University Hospital, V uvalu 84, 15006 Prague 5, Czech Republic

4 Institute of Physiology of the Czech Academy of Sciences, Videnska 1083, 14220 Prague, Czech Republic

5 Institute of Computer Science, Czech Academy of Sciences, Pod vodarenskou vezi 271/2, 18207 Prague, Czech Republic

$\begin{array}{ll}\text { Abbreviations } \\ \text { 17 } \beta \text {-HSD10 } & \begin{array}{l}\text { 17 } \beta \text {-hydroxysteroid dehydrogenase type 10 } \\ \text { PINK1 }\end{array} \\ & \begin{array}{l}\text { Phosphatase and tensin homologue-induced } \\ \text { putave kinase 1 }\end{array} \\ \text { A } \beta & \text { Amyloid } \beta \\ \text { AD } & \text { Alzheimer's disease } \\ \text { CSF } & \text { Cerebrospinal fluid } \\ \text { Tg } & \text { Transgenic } \\ \text { WT } & \text { Wild type } \\ \text { cypD } & \text { Cyclophilin D } \\ \text { MPTP } & \text { Mitochondrial permeability transition pore } \\ \text { SPR } & \text { Surface plasmon resonance } \\ \text { SA } & \text { Sodium acetate } \\ \text { MES } & \text { 2-(N-morpholino)ethanesulfonic acid }\end{array}$

Abbreviations

17ß-HSD10 17 3 -hydroxysteroid dehydrogenase type 10 putative kinase 1

Amyloid $\beta$

Alzheimer's disease

Cerebrospinal fluid

Transgenic

Wild type

Cyclophilin D

Mitochondrial permeability transition pore

Sodium acetate

2-(N-morpholino)ethanesulfonic acid 


$\begin{array}{ll}\text { HEPES } & \begin{array}{l}\text { 2-[4-(2-Hydroxyethyl)piperazin-1-yl] } \\ \text { ethanesulfonic acid }\end{array} \\ \text { PBS } & \begin{array}{l}\text { Phosphate buffer } \\ \text { Ethanolamine }\end{array} \\ \text { BSA } & \begin{array}{l}\text { Bovine serum albumin } \\ \text { OEG }\end{array} \\ \text { Oligo-ethylene glycol } \\ \text { NHS } & \text { N-hydroxysuccinimide } \\ \text { EDC } & \begin{array}{l}\text { 1-Ethyl-3-(3-dimethylaminopropyl)-carbod- } \\ \text { iimide hydro-chloride }\end{array} \\ \text { Q-water } & \text { Deionised water } \\ \text { SAM } & \text { Self-assembled monolayer } \\ \text { ELISA } & \text { Enzyme-linked immunosorbent assay } \\ \text { IgG } & \text { Immunoglobulin } \\ \text { HRP } & \text { Horseradish peroxidase } \\ \text { MCI-others } & \text { Mild cognitive impairment not related to } \\ & \text { AD } \\ \text { MCI-AD } & \text { Mild cognitive impairment related to AD } \\ \text { ADD } & \text { Alzheimer's disease dementia } \\ \text { FTLD } & \text { Frontotemporal lobar degeneration }\end{array}$

\section{Introduction}

The nucleus-encoded mitochondrial matrix protein $17 \beta$-hydroxysteroid dehydrogenase type 10 (17 $\beta$-HSD10) is an essential protein operating via multiple enzymatic as well as non-enzymatic functions. Its deficiency, marked overexpression or loss of enzymatic function is associated with various pathologies [1-3]. Cytosolic 17ß-HSD10 is imported into the mitochondrial matrix via phosphatase and tensin homologue-induced putative kinase 1 (PINK1) mediated Parkin pathway [4, 5]. It has been suggested that direct interactions with Parkin protein play a key role in the regulation of levels of mitochondrial 17 $\beta$-HSD10 and that Parkin overproduction increases $17 \beta$-HSD10 levels in the matrix [5]. Since Pink1-mediated Parkin pathway is involved also in the regulation of mitophagy and $17 \beta$-HSD10 overproduction protects mitochondria against their degradation, it appears that mitochondrial levels of $17 \beta$-HSD10 could be one of mechanisms by which Parkin preserves mitochondrial quality $[5,6]$.

$17 \beta-H S D 10$ is known as a binding partner of amyloid $\beta$ (A $\beta$ ) peptides, accumulated in the brains of individuals with Alzheimer's disease (AD), which can lead among others to mitochondrial dysfunction [e.g., 7]. Experimental results revealed overexpression of $17 \beta-\mathrm{HSD} 10$ especially in cortical or hippocampal regions of AD patients when compared to age-matched controls $[8,9]$ which is also reflected by increased concentrations in cerebrospinal fluid (CSF) [10-12]. Mutual interactions of 17 $\beta$-HSD10 and $\mathrm{A} \beta$ can be documented by many experiments in vitro [e.g., 2, 7, 9, 13-19], by their co-localization in brain mitochondria of $\mathrm{AD}$ patients or of transgenic $(\mathrm{Tg})$ animal models of $\mathrm{AD}[9]$ and also by detection $17 \beta-\mathrm{HSD} 10-\mathrm{A} \beta$ complexes occurring in CSF $[10,11]$. Experiments on $\mathrm{Tg}$ animals overexpressing $17 \beta$-HSD10 when compared to corresponding wild-type (WT) controls indicate its neuroprotective role against oxidative stress. However, double $\mathrm{Tg}$ animals overexpressing $17 \beta$-HSD10 and mutant human amyloid precursor protein display exaggerated AD-like pathology [7] and suggest that both overexpressed $17 \beta$ HSD 10 and accumulated $A \beta$ in mitochondria could play negative roles in mitochondrial dysfunction seen in $\mathrm{AD}$ [17]. With respect to the above-mentioned mutual interactions of $17 \beta$-HSD 10 and $A \beta$, experimental results indicate that D loop of $17 \beta$-HSD10 (approximately 95 to 113 residues) and residues 12-24 of $A \beta$ play important role here $[2,7,9,13,15,17-19]$. Monomeric as well as oligomeric $\mathrm{A} \beta$ peptides can bind to $17 \beta-\mathrm{HSD} 10$ with $\mathrm{K}_{\mathrm{D}}$ about $40-80$ $\mathrm{nM}$ and the binding results in a distortion of $17 \beta$-HSD10 molecule including deformation of D loop and binding pocket for co-factor nicotinamide adenine dinucleotide [2, $7,14,15,18]$. It seems that oligomeric $\mathrm{A} \beta$ peptides, rather than monomeric $A \beta$, are able to significantly inhibit enzymatic activity of $17 \beta$-HSD $10[2,7,18]$.

It was hypothesised that $17 \beta-\mathrm{HSD} 10$ in the mitochondrial matrix binds to cyclophilin D (cypD) and that by preventing its translocation to the inner mitochondrial membrane it can regulate the opening of the mitochondrial permeability transition pore (MPTP) mediated by cypD [20]. Although interactions of $17 \beta-\mathrm{HSD} 10$ and cypD were predicted indirectly by co-immunoprecipitation and colocalization [20], the binding between 17 $\beta$-HSD 10 and cypD has not yet been confirmed experimentally. On the other hand, previous data found mutual interactions of cypD and $\mathrm{A} \beta$ in direct experiments in vitro using surface plasmon resonance (SPR) biosensor, and their co-localization in cortical mitochondria of AD patients and Tg animal models of $\mathrm{AD}[17,21,22]$. It seems that oligomeric $\mathrm{A} \beta$ peptides have a higher affinity for binding to cypD than monomeric fragments [21]. Experimental results obtained on Tg animal model of AD suggest that the regulation of cypD by $17 \beta-H S D 10$ could be influenced by $A \beta$ accumulation in mitochondria and could lead to increased translocation of cypD from the matrix to the inner mitochondrial membrane [17].

The main aim of the present study was (i) to determine the kinetic parameters of the interaction between $17 \beta$ HSD10 and cypD in vitro using the SPR biosensor method and (ii) to estimate the levels of $17 \beta-H S D 10-$ cypD complexes formed in vivo either in brain mitochondria isolated from $\mathrm{Tg}$ rat model of $\mathrm{AD}$ or in CSF samples of $\mathrm{AD}$ patients in order to clarify changes occurring in brain mitochondria of individuals with $\mathrm{AD}$ in more detail and to evaluate CSF levels of 17 $\beta$-HSD10-cypD complexes as a promising diagnostic biomarker of AD. 


\section{Materials and Methods}

\section{SPR Biosensor}

\section{Reagents}

Sodium acetate $\left(\mathrm{SA}_{10}, 10 \mathrm{mM}, \mathrm{pH} 5\right), 2-(\mathrm{N}-$ morpholino) ethanesulfonic acid (MES, 10 mM, pH 5), 2-[4-(2-hydroxyethyl)piperazin-1-yl]ethanesulfonic acid (HEPES, 10 $\mathrm{mM}$, pH 7.4), phosphate buffer (PBS, $1.4 \mathrm{mM} \mathrm{KH} \mathrm{PO}_{4}, 8$ $\mathrm{mM} \mathrm{Na} \mathrm{HPO}_{4}, 2.7 \mathrm{mM} \mathrm{KCl}$ and $\left.137 \mathrm{mM} \mathrm{NaCl}, \mathrm{pH} 7.4\right)$, $\mathrm{NaCl}, \mathrm{KCl}, \mathrm{MgCl}_{2}$, ethanolamine (EA) and bovine serum albumin (BSA) were purchased from Sigma-Aldrich, USA, in molecular biology grade or higher. Ethanol for spectroscopy (purity $99.9 \%$ or greater) was purchased from Merck, USA. Oligo-ethylene glycol (OEG) thiols terminated with carboxyl group ( $\left.\mathrm{HS}-\mathrm{C}_{11}-(\mathrm{EG})_{6}-\mathrm{OCH}_{2}-\mathrm{COOH}\right)$ and hydroxyl group (HS-C $\left.{ }_{11}-(\mathrm{EG})_{4}-\mathrm{OH}\right)$ were purchased from Prochimia, Poland. N-hydroxysuccinimide (NHS) and 1-ethyl-3-(3-dimethylaminopropyl)-carbodiimide hydrochloride (EDC) were purchased from GE Healthcare, USA. Human recombinant $17 \beta$-HSD10 and cypD proteins and monoclonal mouse antibody against mitochondrial cypD (anti-cypD) were purchased from Fitzgerald, USA. A $\beta 142$ fragment was obtained from AnaSpec, USA. All buffers were prepared using deionized water (Q-water, $18 \mathrm{M} \Omega / \mathrm{cm}$ resistivity, Direct-Q UV3, Millipore, USA), phosphate buffer with high ionic strength $\left(\mathrm{PBS}_{\mathrm{NaCl}}\right)$ was prepared from PBS by increasing concentration of $\mathrm{NaCl}$ to $750 \mathrm{mM}$, HEPES $_{\mathrm{BSA}}$ was prepared from HEPES by addition of $250 \mu \mathrm{g} / \mathrm{ml} \mathrm{BSA}, 15 \mathrm{mM} \mathrm{KCl}$ and $0.1 \mathrm{mM} \mathrm{MgCl}_{2}$.

\section{Instrumentation}

In this study, we used a laboratory 6-channel SPR platform based on the wavelength spectroscopy of surface plasmons (Plasmon VI) with dispersionless microfluidics $[23,24]$ developed at the Institute of Photonics and Electronics, Prague. In the SPR sensor, the angle of incidence of the light beam is fixed and the SPR dip is observed in the spectrum of polychromatic light coupled to a surface plasmon. The sensor response is expressed in terms of the shift in the wavelength at which the SPR dip occurs. This response is sensitive to changes in the refractive index caused by the binding of molecules to the surface of an SPR chip. A shift of $1 \mathrm{~nm}$ in the SPR wavelength represents a change in the protein surface coverage of $17 \mathrm{ng} /$ $\mathrm{cm}^{2}$ [25]. SPR chips used in this work were prepared by coating microscope glass slides (Marienfeld, Germany) with thin layers of titanium (1-2 nm) and gold (48 nm) via e-beam evaporation in vacuum. All SPR experiments were performed at $25^{\circ} \mathrm{C}$ and a flow rate of $20 \mu \mathrm{l} / \mathrm{min}$.

\section{Functionalization of an SPR Chip}

The surface of SPR chips was functionalized with a selfassembled monolayer (SAM) of mixed carboxy-terminated and hydroxy-terminated OEG thiols, on which anti-cypD was immobilized using the amino-coupling as described previously [25]. Briefly, a 3:7 molar mixture of $\mathrm{HS}-\mathrm{C}_{11}-(\mathrm{EG})_{6}{ }^{-}$ $\mathrm{OCH}_{2}-\mathrm{COOH}$ and $\mathrm{HS}-\mathrm{C}_{11}-(\mathrm{EG})_{4}-\mathrm{OH}$ thiols was dissolved in ethanol at a total concentration of $0.2 \mathrm{M}$. SPR chip was immersed in the thiol mixture for $10 \mathrm{~min}$ at $40{ }^{\circ} \mathrm{C}$ and stored for at least $12 \mathrm{~h}$ at room temperature. Then, the chip was rinsed with ethanol and Q-water and mounted into the SPR biosensor. The mixture of $12.5 \mathrm{mM}$ NHS and $62.5 \mathrm{mM}$ EDC (in Q-water) was injected for $10 \mathrm{~min}$ to the surface of SPR chip in order to activate carboxylic groups. Then, anti-cypD at a concentration of $5 \mu \mathrm{g} / \mathrm{ml}$ in $\mathrm{SA}_{10}$ was injected for $12 \mathrm{~min}$ to covalently attach anti-cypD to the activated carboxylic groups. The surface was consequently washed by $\operatorname{PBS}_{\mathrm{NaCl}}(5$ $\mathrm{min}$ ) to remove the non-covalently bound molecules from a surface of SPR chip and by $0.5 \mathrm{M} \mathrm{EA} \mathrm{(5} \mathrm{min)} \mathrm{to} \mathrm{deactivate}$ the remaining active esters.

\section{Interaction Between cypD and 17 $\beta-H S D 10$}

Interaction between cypD and $17 \beta$-HSD10 proteins was studied in the direct fashion using the detection and reference channels. Initially, MES was injected for $10 \mathrm{~min}$ into both channels functionalized with anti-cypD. Then, $2 \mu \mathrm{g} / \mathrm{ml}$ cypD was injected into the detection channel until the sensor response of $1.5 \mathrm{~nm}$ was achieved, while MES was continuously pumped through the reference channel. Then, MES (20 min) and $\mathrm{PBS}_{\mathrm{NaCl}}(5 \mathrm{~min})$ were injected into both chan-

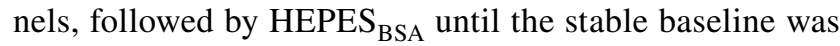
obtained. Solutions of $17 \beta$-HSD10 at concentrations of 30 , $50,150,300$, and $500 \mathrm{nM}$ in $\mathrm{HEPES}_{\mathrm{BSA}}$ were prepared and incubated for $10 \mathrm{~min}$ at $37^{\circ} \mathrm{C}$ to ensure the full tetramerization of $17 \beta$-HSD10 [26]. Then, $400 \mu \mathrm{l}$ of HEPES BSA $_{\text {was }}$ added to the solution to obtain the $17 \beta$-HSD10 at final concentrations of $6,10,30,60$, and $100 \mathrm{nM}$. These solutions were injected for $10 \mathrm{~min}$ into both detection (with attached cypD) and reference (without attached cypD) channels to monitor the association phase, followed by exposing the sensor surface to $\mathrm{HEPES}_{\mathrm{BSA}}$ for $15 \mathrm{~min}$ to characterize the dissociation phase. The reference compensated curves (sensor responses from the reference channels were subtracted from those obtained in the particular detection channels) were globally fitted using BIAevaluation software version 4.1 and 1:1 Langmuir model considering mass transport effects. In order to provide the positive control for our biosensor experiments, we performed a control experiment in which 
we observed the binding of $A \beta 1-42$ to the cypD immobilized on the SPR sensor surface. In the immobilization step, $2 \mu \mathrm{g} / \mathrm{ml}$ cypD was injected into the detection channel until the sensor response leveled off $(\sim 5 \mathrm{~nm})$, while MES was continuously pumped through the reference channel. Then, MES (20 min) and $\mathrm{PBS}_{\mathrm{NaCl}}(5 \mathrm{~min})$ were injected into both channels, followed by HEPES $\mathrm{BSA}_{\mathrm{B}}$ until the stable baseline was obtained. In the detection step, A $\beta$ 1-42 (500 mM, incubated for $1 \mathrm{~h}$ at $37^{\circ} \mathrm{C}$ ) was injected into detection and reference channels and the binding was observed for $10 \mathrm{~min}$.

\section{Co-immunoprecipitation Experiment to Detect Interaction of $17 \beta-H S D 10$ and cypD}

Mixtures of human full length recombinant $17 \beta$-HSD10 protein (His tag) (Fitzgerald Industries International) and of human full length cypD protein (His tag) (Fitzgerald Industries International) in PBS (concentration $20 \mu \mathrm{g} / \mathrm{ml}$ each; in $100 \mu \mathrm{l}$ ) were incubated for $2 \mathrm{~h}$ at room temperature and then mixed with $2 \mu \mathrm{l}$ with either polyclonal rabbit anti-17 $\beta$-HSD10 (Flarebio) or monoclonal mouse anti-cypD (Fitzgeral Industries International). Incubation was continued for another $2 \mathrm{~h}$ and mixtures were then transferred to tubes containing Protein A-sepharose (Sigma) pellet (approx. $50 \mu \mathrm{l})$ and incubated while rotating overnight at $4{ }^{\circ} \mathrm{C}$. Samples were centrifuged $(8000 \times g$ for $5 \mathrm{~min}$ ), supernatants collected and the pellets were washed 3 times with PBS by centrifugation. Samples were then dissolved in Laemli denaturating sample buffer, electrophoresed in precast gradient 5-15\% polyacrylamide Mini-Protean TGX gels and blotted to nitrocellulose in Trans-Blot Turbo according to Bio-Rad protocols. Blotted membranes were quenched by incubation in $10 \%$ soya milk in PBS, washed, incubated overnight at $4{ }^{\circ} \mathrm{C}$ in sealed pouch with either anti-17ß-HSD10 or anticypD (dilution 1:1000 in both cases), washed and incubated with respective anti-immunoglobulin ( $\mathrm{IgG})$-horseradish peroxidase (HRP) conjugate (either goat polyclonal anti-mouse IgG/HRP or goat polyclonal anti-rabbit IgG/HRP, dilutions 1:5000, both from Dako) for $2 \mathrm{~h}$. To reveal immunoprecipitated proteins, blots were incubated in $20 \mathrm{ml} \mathrm{PBS}$ containing $10 \mathrm{mg}$ of 3,3-diaminobenzidine (Sigma) plus $10 \mu \mathrm{l}$ of 30\% hydrogen peroxide and stained membranes were after washing imaged by ChemiDoc XRS + Imager (Bio-Rad).

\section{Animals and Isolation of Mitochondria}

Ten 11-month old Tg homozygous male McGill-R-Thy1APP rats and ten age-matched WT male Wistar controls (all from PsychoGenics, Austria) or 7-month old male Wistar rats (five control animals for preparation of internal standards, from Velaz, Czech Republic) were housed in cages (2 rats per cage) in a temperature-controlled room $\left(21-22^{\circ} \mathrm{C}\right)$, with a 12:12 h light/dark regime (lights on at 7:00 a.m.) with free access to food (ST-1 diet) and water. All manipulations were performed according to the Guidelines of the European Union Council (86/609/EU). Rats were sacrificed by cervical dislocation, decapitated, and the brains rapidly removed from the skulls. The left hemispheres (without the cerebellum, medulla oblongata and bulbus olfactorius) were dissected on an ice-cold plate, weighed and immediately used for isolation of mitochondria. Mitochondria were isolated by discontinuous Percoll density gradient [27]. Concentration of total mitochondrial proteins was estimated by means of Coomassie Brilliant Blue G-250 [28]. Mitochondria isolated from twenty 11-month old male rats (particular samples) and two 7-month old male rats (one mixed sample which aliquots are used as internal standards) were resuspended in the buffer $\left(0.25 \mathrm{M}\right.$ sucrose, $0.5 \mathrm{mM} \mathrm{K}^{+}$-EDTA, $10 \mathrm{mM}$ TRIS, pH 7.4) and adjusted to mitochondrial protein concentration of $9 \mathrm{mg} / \mathrm{ml}$. Particular aliquots of mitochondria (250 $\mu \mathrm{l})$ were stored at $-40{ }^{\circ} \mathrm{C}$ until assayed.

\section{Human CSF Samples}

All experiments were conducted in accordance with The Declaration of Helsinki. The study was approved by the Ethical Committees of Motol University Hospital, in accordance with the Laws 129/2003 and 130/2003 of the Czech Republic. Written informed consent was obtained from all study participants, either personally or by proxy. CSF samples were collected from 171 patients undergoing lumbar puncture as a part of their routine diagnostic work-up (basic characteristics are shown in Table 1). Patients were divided into five groups. The first group of 12 cognitively normal controls consisted of neurological patients with normal cognitive functions and normal basic CSF findings undergoing

Table 1 Characteristics of patients providing CSF samples

\begin{tabular}{lrlll}
\hline Groups & $\mathrm{n}$ & $\mathrm{Sex}(\mathrm{M} / \mathrm{F})$ & Age (years) & MMSE score \\
\hline Controls & 12 & $6 / 6$ & $67.6 \pm 6.6$ & $28.5 \pm 0.9$ \\
MCI-others & 17 & $11 / 6$ & $68.7 \pm 9.9$ & $27.2 \pm 1.6$ \\
MCI-AD & 44 & $21 / 23$ & $72.2 \pm 6.7$ & $25.5 \pm 1.8^{* * *}$ \\
ADD & 56 & $18 / 38$ & $71.0 \pm 7.9$ & $20.6 \pm 3.7^{* * *}$ \\
FTLD & 42 & $17 / 25$ & $64.9 \pm 7.5$ & $21.0 \pm 6.2^{* * *}$ \\
Totally: & 171 & $73 / 98$ & $\mathrm{p}<0.001$ & $\mathrm{p}<0.001$ \\
Welch test & & & & \\
\hline
\end{tabular}

Data are presented as the mean $\pm \mathrm{SD}$

Statistical significance (Bonferroni adjusted t-test, separate variance) was calculated with respect to controls (*** adjusted $\mathrm{p}<0.001)$. Group of ADD patients was significantly older when compared to FTLD people.

$M$ males, $F$ females, $M M S E$ mini-mental state examination, $M C I$ others individuals with mild cognitive impairment not related to Alzheimer's disease, $M C I-A D$ mild cognitive impairment due to Alzheimer's disease, $A D D$ Alzheimer's disease dementia, FTLD Frontotemporal lobar degeneration 
lumbar puncture for various medical reasons (e.g. facial palsy, headache) and of cognitively normal individuals undergoing elective orthopedic surgery in spinal anesthesia who agreed to give $6 \mathrm{ml}$ of CSF for research purposes during the procedure. Only subjects with normal levels of A $\beta 1-42$, total- $\tau$ and phospho- $\tau$ and with normal basic analysis of CSF were included in the control group. The second group consisted of 17 patients with mild cognitive impairment not related to AD (MCI-others) and the third group of 44 patients fulfilled the criteria for mild cognitive impairment due to AD (MCI-AD) [29]. The fourth group consisted of 56 patients with probable AD dementia (ADD) [30]. And finally the fifth group comprised 42 patients with Frontotemporal lobar degeneration (FTLD) [31]. All patients underwent complex diagnostic process including neuropsychological examination by neuropsychological battery (including the Mini Mental State Examination test), brain MRI, neurological examination and routine blood tests. All CSF samples were obtained by lumbar puncture with an atraumatic needle in the lying position. The first $3 \mathrm{ml}$ was used for routine analysis (cell count, total protein etc.), and the remaining sample was centrifuged and frozen in polypropylene tubes at $-80{ }^{\circ} \mathrm{C} 30 \mathrm{~min}$ after the puncture, until required for further analyses. Particular aliquots of mixed CSF samples from eight people discarded from the study (four men and four women) were used as internal standards.

\section{Enzyme-Linked Immunosorbent Assay (ELISA)}

\section{Quantitative Competitive ELISA for Estimation of 17 $\beta$-HSD10 in Rat Brain Mitochondrial Fraction}

A full length rat recombinant protein $17 \beta-H S D 10$ (Flarebio) was dissolved in carbonate buffer $\left(75 \mathrm{mM} \mathrm{NaHCO}_{3}, 25\right.$ $\mathrm{mM} \mathrm{Na}_{2} \mathrm{CO}_{3}, \mathrm{pH}$ 9.5). The solution was applied to 96-well polystyrene plates (Nunc Immuno Plate Maxisorp, $86 \mathrm{ng}$ of protein per well) and incubated for $4 \mathrm{~h}$ at room temperature (shaker IKA, MTS 2/4). Plates were subsequently washed three times with PBS $\left(2.8 \mathrm{mM} \mathrm{Na}_{2} \mathrm{HPO}_{4}, 7.2 \mathrm{mM} \mathrm{NaH}_{2} \mathrm{PO}_{4}\right.$, $100 \mathrm{mM} \mathrm{NaCl}, \mathrm{pH}$ 7.2). Nonspecific binding was suppressed by incubation with blocking solution $(10 \mathrm{mg} / \mathrm{ml}$ of bovine serum albumin in carbonate buffer) for $1 \mathrm{~h}$ at room temperature followed by overnight incubation at $10^{\circ} \mathrm{C}$. Prior to the assay, the plates were washed three times with washing solution (PBS and $0.05 \%$ Tween 20). A standard curve was prepared using 138 to $4839 \mathrm{ng}$ of rat recombinant protein $17 \beta$-HSD10 dissolved in 10\% dimethyl sulfoxide. Various volumes of standards, $50 \mu \mathrm{l}$ of particular samples $(100 \mu \mathrm{l}$ of mitochondrial fraction and $20 \mu \mathrm{l}$ of redistilled water and $10 \mu \mathrm{l}$ of $15 \% \mathrm{n}$-dodecyl $\beta$-D-maltoside) and $50 \mu \mathrm{l}$ of internal standards (prepared in accordance with the samples) were pipetted in duplicates and adjusted to $100 \mu \mathrm{l}$ by $10 \%$ dimethyl sulfoxide. Plates were subsequently incubated with primary antibody (polyclonal rabbit anti-17 $\beta$-HSD10 reacting with human, mouse, rat and monkey protein, Flarebio, dilution 1:4000) for $4 \mathrm{~h}$ at room temperature. Plates were washed four times with washing solution (PBS with $0.05 \%$ Tween 20), and secondary antibody (polyclonal swine antirabbit IgG/HRP (DakoCytomation, dilution 1:6000) was added. After a 1-h incubation at room temperature, the plates were washed four times with washing solution. Subsequently, substrate solution (3, 3',5 ,5'-tetramethylbenzidine liquid substrate system for ELISA, Sigma) was added and plates were incubated for $20 \mathrm{~min}$ at room temperature. The reaction was stopped with $0.5 \mathrm{M} \mathrm{H}_{2} \mathrm{SO}_{4}$ and plates were measured at the wavelength of $450 \mathrm{~nm}$ using an automated plate reader (Multiskan EX, Thermo). After the subtraction of the blank, levels of $17 \beta$-HSD10 were estimated in particular samples. The detection limit was determined to be about $20 \mathrm{ng}$ of the protein. Intra- and inter-assay variability was determined to be $3.7 \%$ and $9.6 \%$ at the control protein level of $277 \mathrm{ng}$.

\section{Quantitative Sandwich ELISA for Estimation of cypD in Rat Mitochondrial Fraction}

Levels of rat cypD were estimated by a kit (MyBioSource). $50 \mu \mathrm{l}$ of samples ( $250 \mu \mathrm{l}$ of mitochondrial fraction and $25 \mu \mathrm{l}$ of $15 \% \mathrm{n}$-dodecyl $\beta$-D-maltoside) were incubated in quadruplicates and measured in accordance with manufacturer's instructions.

\section{Semi-quantitative Sandwich ELISA for Estimation of Total $A \beta$ in Rat Mitochondrial Fraction}

Plate was coated by goat anti-mouse IgG (Fitzgerald Industries International, $1 \mu \mathrm{g}$ per well) and then by monoclonal mouse anti-A $\beta$ 13-28 recognizing mouse, rat and human A $\beta$ (Sigma, $100 \mathrm{ng}$ per well). $100 \mu \mathrm{l}$ of samples or internal standards ( $225 \mu \mathrm{l}$ of mitochondrial fraction and $45 \mu \mathrm{l}$ of $15 \%$ $\mathrm{n}$-dodecyl $\beta$-D-maltoside in both cases) were incubated in duplicates for $5 \mathrm{~h}$. Subsequently, second primary antibody (polyclonal rabbit anti-A $\beta$ 1-14 reacting with mouse, rat and human fragments, Abcam, dilution 1:9000) and lately secondary antibody (swine anti-rabbit IgG/HRP, DakoCytomation, dilution 1:6000) were applied. After the subtraction of the blank, the values were compared to those from the internal standards and expressed in percentage.

\section{Semi-quantitative Sandwich ELISA for Estimation of $17 \beta$-HSD10-cypD or $17 \beta$-HSD10-Total A $\beta$ Complexes in Rat Mitochondrial Fraction}

Two plates were coated by a capture antibody against $17 \beta$ HSD10 (polyclonal rabbit anti-ERAB reacting with human, mouse, rat and monkey protein, Flarebio) dissolved in 
carbonate buffer. Coating solution (246 ng of antibody per well) was applied and plates were incubated for $5 \mathrm{~h}$ at room temperature. $100 \mu \mathrm{l}$ of samples or internal standards (250 $\mu \mathrm{l}$ of mitochondrial fraction and $150 \mu \mathrm{l}$ of redistilled water and $25 \mu \mathrm{l}$ of $15 \% \mathrm{n}$-dodecyl $\beta$-D-maltoside) were incubated in duplicates for $5 \mathrm{~h}$. Subsequently, second primary antibody against cypD (monoclonal mouse anti-PPIF recognizing rat and human protein, Abnova, dilution 1:2133) and lately secondary antibody (polyclonal rabbit anti-mouse IgG/HRP, Dako, dilution 1:6000) were applied on the first plate. Analogously, second primary antibody against total $\mathrm{A} \beta$ (monoclonal mouse anti-A $\beta$ 13-28 recognizing mouse, rat and human fragments, Sigma, dilution 1:2666) and lately secondary antibody (polyclonal rabbit anti-mouse IgG/HRP, Dako, dilution 1:6000) were added to the second plate. After the subtraction of the blank, the values were compared to those from the internal standards and expressed in percentage.

\section{Quantitative Sandwich ELISA for Estimations of Levels of $A \beta$ $1-42, \tau$ and Phospho- $\tau$ in Human CSF}

Levels of human A $\beta 1-42$, total $\tau$ and $\tau$ phosphorylated at position 181 were estimated by three kits (Fujirebio) according to the manufacturer's instructions.

\section{Semi-quantitative Sandwich ELISA for Estimation of 17 $\beta$-HSD10-cypD Complexes in Human CSF}

Plate was coated by goat anti-rabbit IgG (Fitzgerald Industries International, $1 \mu \mathrm{g}$ per well) and then by polyclonal rabbit anti-17ß-HSD10 (polyclonal rabbit anti-ERAB recognizing human, mouse, rat and monkey protein, Flarebio, $200 \mathrm{ng}$ per well). $100 \mu$ of redistilled water or of CSF samples were incubated in duplicates for $4 \mathrm{~h}$. Subsequently, second primary antibody against cypD (monoclonal mouse anti-PPIF recognizing mouse, rat and human protein, Abnova, dilution 1:2133) and lately secondary antibody (donkey anti-mouse IgG/HRP, Dako, dilution 1:8000). After the subtraction of the blank, the values were compared to those from the internal standards (mixed CSF samples of totally eight people discarded from the study) and expressed in percentage.

\section{Transmission Electron Microscopy (TEM)}

Sample of mitochondria was stored in $0.25 \mathrm{M}$ sucrose, 0.5 $\mathrm{mM} \mathrm{K}{ }^{+}$-EDTA, $10 \mathrm{mM}$ Tris (pH 7.4) with $10 \%$ dimethyl sulfoxide in protein concentration of $5 \mathrm{mg} / \mathrm{ml}$ at $-80{ }^{\circ} \mathrm{C}$. Before TEM analysis, the sample was tempered to room temperature and centrifuged at $14,000 \times \mathrm{g}$ for $10 \mathrm{~min}$. The pellet was fixed with $2.5 \%$ glutaraldehyde in $0.1 \mathrm{M}$ cacodyladate buffer with $5 \mathrm{mM} \mathrm{CaCl}_{2}$ and embedded in $2 \%$ agar. The second fixation was done with $1 \%$ osmium tetroxide in
$0.1 \mathrm{M}$ cacodyladate buffer, serial dehydration and embedding into epoxy resin. The images were acquired with FEI Morgagni 268 transmission electron microscope operated at $80 \mathrm{kV}$ equipped with Mega View III CCD camera (pixel size $6.45 \times 6.45 \mu \mathrm{m})$.

\section{Statistical Analysis}

Statistical analysis was performed using BMDP statistical software. Parametric Welch test for global and Bonferroni adjusted t-test (separate variance) for pairwise comparisons (program 7D) were used (*Adjusted $\mathrm{p}<0.050, * *$ Adjusted $\mathrm{p}<0.010$, ***Adjusted $\mathrm{p}<0.001)$. In addition, correlation analysis (program 6D) was applied. The equality of correlation coefficients (Rs) in two groups was examined using the test based on Fisher's Z-transformation ( $\mathrm{Z}$ test, two-tailed version) [32]. Sensitivity and specificity using Receiver Operating Characteristic (ROC) curve analysis were calculated in MS Excel in accordance with MedCalc statistical software manual. Data are presented as means \pm S.D.

\section{Results}

\section{SPR Biosensor}

We used the SPR biosensor to demonstrate that mitochondrial proteins cypD and $17 \beta$-HSD10 interact with each other and to determine kinetic parameters of the interaction. In the used detection format, we injected different concentrations of 17 -HSD10 into both the detection (immobilized cypD) and reference (absence of cypD) channels. Figure 1i shows significantly higher sensor response in the detection channel than in the reference channel, which indicates specific interaction between $17 \beta-H S D 10$ and cypD. The data obtained in the reference channel were subtracted from those obtained in the detection channel to compensate for bulk refractive index changes and non-specific binding to the surface. The reference-compensated binding curves obtained for the set of five different concentrations of $17 \beta-$ HSD10 were further used to determine the kinetic parameters of the interaction between 17ß-HSD10 and cypD (Fig. 1ii). The association rate constant $k_{a}$, dissociation rate constant $k_{d}$, and dissociation equilibrium constant $K_{d}$ were determined as $2.0 \times 10^{5}$ $\mathrm{M}^{1} \mathrm{~s}^{-1}, 5.8 \times 10^{4} \mathrm{~s}^{-1}$, and $3.5 \times 10^{-10} \mathrm{M}$, respectively. In order to confirm that the immobilized cypD is capable of interacting with its binding partners, we used $\mathrm{A} \beta$ 1-42 as a positive control (A $\beta$ 1-42 is known to specifically interact with cypD [21]). The corresponding sensorgram is shown in the Fig. 1iii and proves that cypD can indeed interact with $A \beta$ 1-42. 
Fig. 1 Data of SPR biosensor demonstrating the binding of $17 \beta$-HSD10 to cypD. Figure demonstrates: (i) the sensor response to binding of $6,10,30$, 60 , and $100 \mathrm{nM} 17 \beta$-HSD10 in the detection (solid lines) and in the reference (dashed lines) channels, (ii) reference-compensated binding curves for the set of the used concentrations of 17 $\beta$-HSD10 (solid lines) and their global fits (dashed lines) and finally (iii) the sensor response to the binding of $A \beta$ $1-42$ in the detection (solid line) and in the reference (dashed line) channel
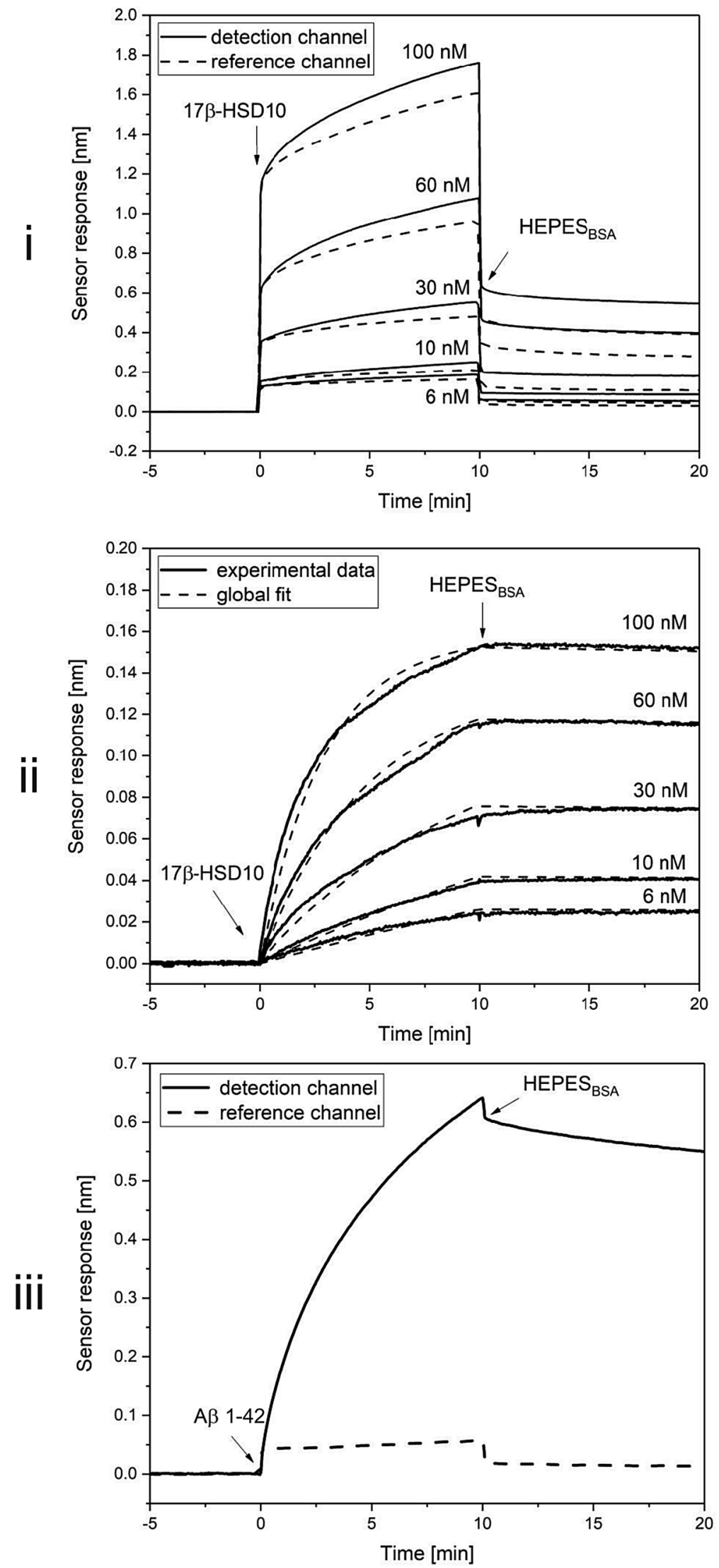


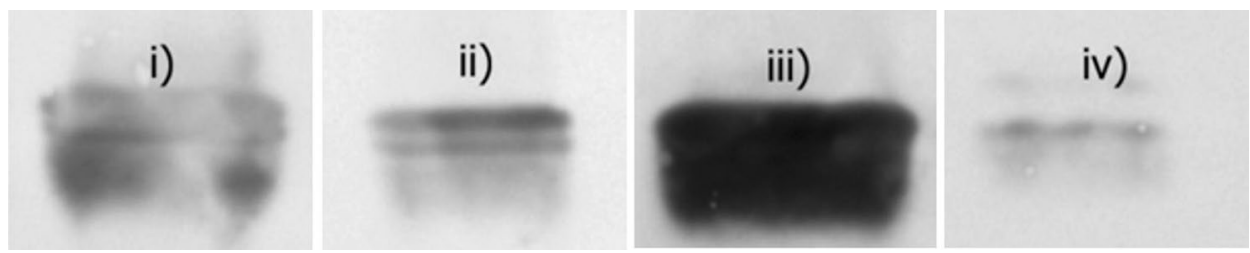

Fig. 2 Demonstration of 17 $\beta$-HSD10-cypD interaction by co-immunoprecipitation. Figure demonstrates: (i) immunoblot of $17 \beta$-HSD10 standard (cca $1 \mu \mathrm{g}$ ), (ii) co-immunoprecipitation of 17ß-HSD10 cypD mix pulled-down by anti-cypD antibody-Protein A-sepharose

\section{Co-immunoprecipitation}

We used also co-immunoprecipitation experiment to demonstrate the interaction of mitochondrial proteins $17 \beta$-HSD10 and cypD. Figure 2 supports notion of such binding (blot ii, blot iv).

\section{Experiments Performed on Rat Brain Mitochondrial Fraction}

TEM documented high purity and intactness of our isolated mitochondria (Fig. 3). Intactness of mitochondria was also supported by enzymatic assays (data not shown). In particular, activities of citrate synthase (a marker of the mitochondrial matrix) and of lactate dehydrogenase (a cytosolic marker) were estimated by kits of Sigma-Aldrich. Citrate synthase assay revealed that $91 \%$ of mitochondria remained their inner membrane intact. Lactate dehydrogenase assay indicated that activity of a cytosolic enzyme was approximately 40-times lower in fraction of purified mitochondria $(37 \mathrm{mU} / \mathrm{ml})$ than in original homogenate $(1381 \mathrm{mU} / \mathrm{ml})$. and revealed by anti-17 $\beta$-HSD10 antibody, (iii) immunoblot of cypD standard (cca $2 \mu \mathrm{g}$ ), and finally (iv) co-immunoprecipitation of 17ßHSD10-cypD mix pulled-down by anti-17 $\beta$-HSD10 antibodyProtein A-sepharose and revealed by anti-cypD antibody

Results of quantitative estimations are seen in Figs. $4 \mathrm{i}$ and ii. Figure $4 \mathrm{i}$ shows levels of $17 \beta$-HSD10 estimated by competitive ELISA. Values of WT rats equaled $3.5 \pm 0.7 \mathrm{ng} /$ $\mu \mathrm{g}$ of mitochondrial proteins, differences between $\mathrm{Tg}$ and WT groups were not statistically significant (Welch test: $\mathrm{p}=0.508$ ). Figure 4ii demonstrates levels of cypD estimated by sandwich ELISA. The values of WT rats equaled $3.0 \pm 0.1 \mathrm{ng} / \mathrm{ml}$ and differences between both groups were not statistically significant again (Welch test: $p=0.091$ ). Results of semi-quantitative ELISA experiments are demonstrated in Figs. 4iii and 5. All values were compared to those from the internal standards and expressed in percentage. Figure 4iii shows total levels of mitochondrial $A \beta$ estimated by a sandwich ELISA. Results indicated the significant increase to $105.0 \%$ in $\mathrm{Tg}$ when compared to WT rats (Welch test: $p=0.006$ ). Figure 5 demonstrates levels of $17 \beta$-HSD $10-$ cypD and $17 \beta$-HSD10-A $\beta$ complexes estimated by sandwich ELISA. While the values of $17 \beta$ HSD10-cypD complexes were significantly decreased in $\mathrm{Tg}$ compared to WT rats (to $76.2 \%, \mathrm{p}=0.012$ ), no significant differences were found in the case of $17 \beta-H S D 10-A \beta$ complexes $(\mathrm{p}=0.072)$.
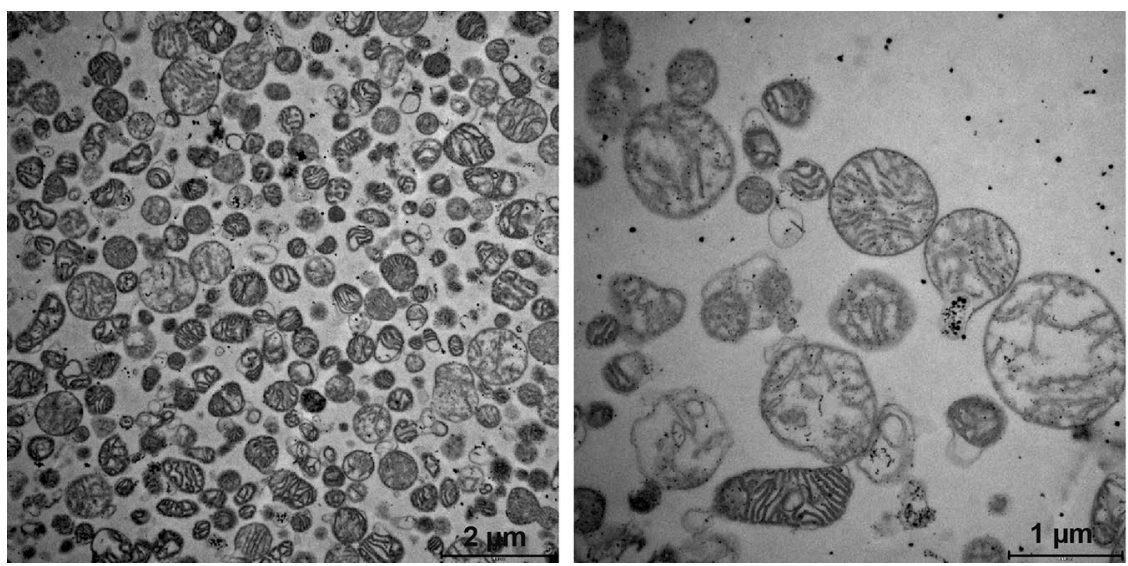

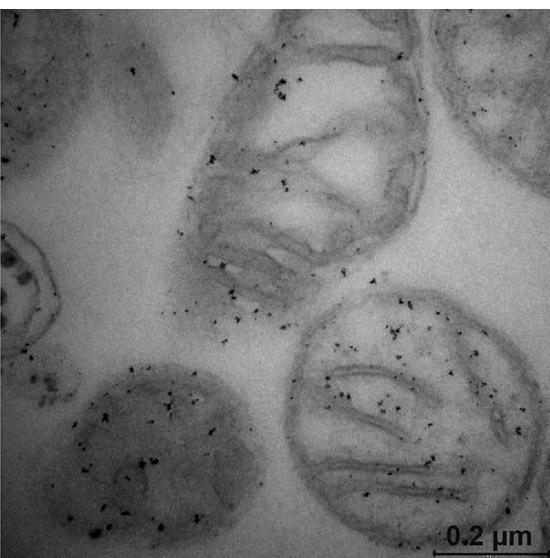

Fig. 3 Pictures of isolated mitochondria by transmission electron microscopy. Transmission electron microscopy (Imaging Methods Core Facility, BIOCEV, Prague) documented high purity and intactness of mitochondria isolated in accordance with the study of Raja- pakse et al. [27]. Sample (mitochondria isolated from three 7-month old male Wistar rats used as internal standards) was stored in $0.25 \mathrm{M}$ sucrose, $0.5 \mathrm{mM} \mathrm{K}^{+}$-EDTA, $10 \mathrm{mM}$ Tris, pH 7.4 with $10 \%$ dimethyl sulfoxide at $-80{ }^{\circ} \mathrm{C}$ (in concentration of $5 \mathrm{mg}$ protein $/ \mathrm{ml}$ ). 

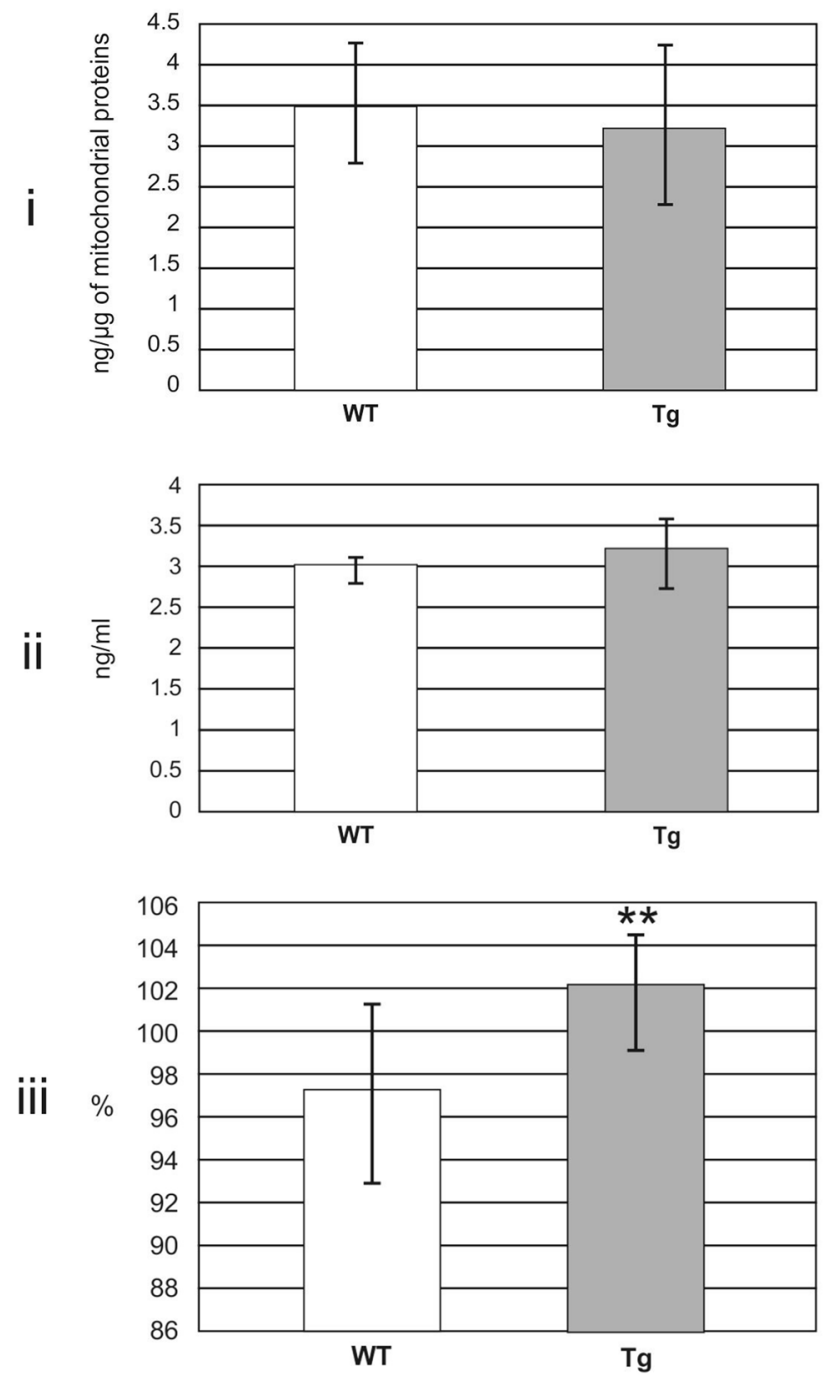

Fig. 4 Levels of 17 $\beta$-HSD10, cypD and $\mathrm{A} \beta$ in rat mitochondrial fraction estimated by ELISA. Data are presented as the mean \pm SD. All values were obtained from $10 \mathrm{WT}$ and $10 \mathrm{Tg}$ (homozygous McGill-R-Thy1-APP) rats. Figure demonstrates: (i) levels of $17 \beta$-hydroxysteroid dehydrogenase type 10 (17 $\beta$-HSD10) estimated by quantitative competitive ELISA (differences between both groups were not statistically significant, Welch test: $p=0.508$ ), (ii) levels of cyclophilin D (cypD) estimated by quantitative sandwich ELISA (differences between both groups were not statistically significant, Welch test: $p=0.091$ ), and finally (iii) total levels of amyloid $\beta(A \beta)$ peptides estimated by semi-quantitative ELISA (differences between both groups were statistically significant, Welch test: $p=0.006$ )

Results of correlation analysis performed on data obtained from rat mitochondrial fraction revealed two significant negative correlations in WT control rats-the first between $17 \beta$-HSD10 and cypD levels $(\mathrm{R}=-0.708$, $\mathrm{p}=0.022)$ and the second between $17 \beta-\mathrm{HSD} 10-\mathrm{cypD}$ and $17 \beta$-HSD10-A $\beta$ complexes $(\mathrm{R}=-0.745, \mathrm{p}=0.013)$. The correlation between $17 \beta$-HSD10 and cypD levels was not significant in $\mathrm{Tg}$ rats $(\mathrm{R}=+0.316, \mathrm{p}=0.374)$ and the result of Z-test supported the significant change between $\mathrm{Tg}$ and
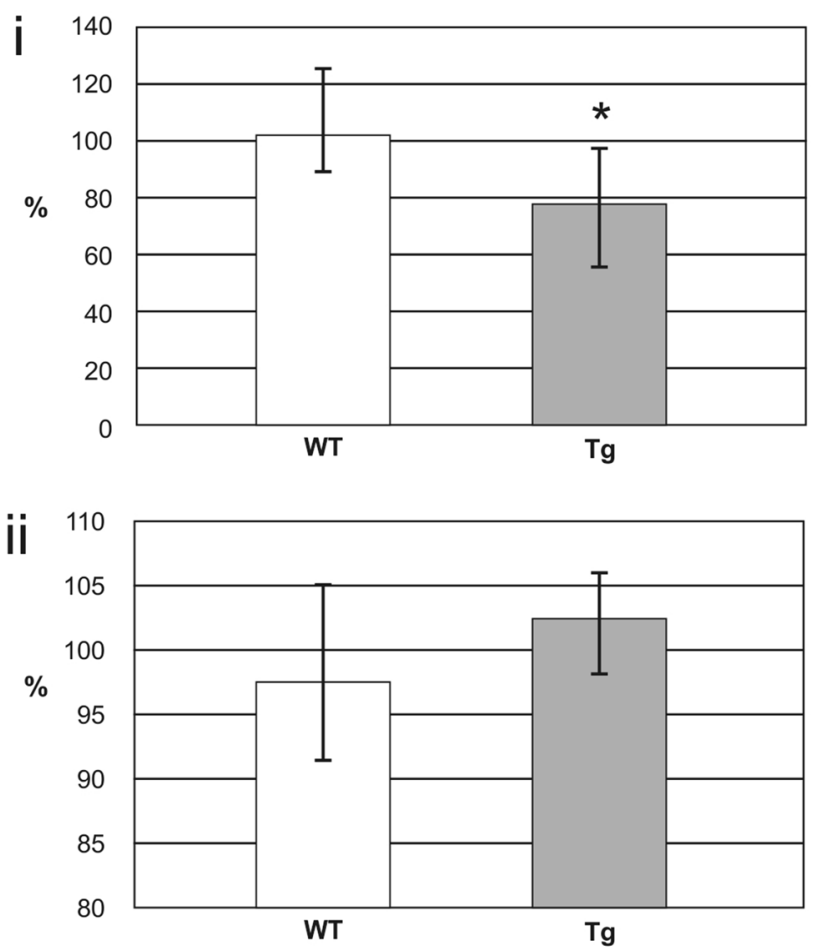

Fig. 5 Levels of $17 \beta-H S D 10-c y p D$ and $17 \beta-H S D 10-A \beta$ complexes in rat mitochondrial fraction estimated by semi-quantitative sandwich ELISA. Data are presented as the mean \pm SD. Levels of two types of complexes, i.e. of 17 $\beta$-hydroxysteroid dehydrogenase type 10 and cyclophilin D (17 $\beta$-HSD10-cypD complexes, experiment (i) and of $17 \beta$-hydroxysteroid dehydrogenase type 10 and amyloid $\beta$ (17 $\beta$-HSD10-A $\beta$ complexes, experiment (ii) were obtained from 10 WT and $10 \mathrm{Tg}$ (homozygous McGill-R-Thy1-APP) rats. The values of 17 $\beta$-HSD10-cypD complexes were significantly decreased in $\mathrm{Tg}$ compared to WT rats (Welch test: $p=0.012$ ). On the contrary, no differences were found in levels of 17 $\beta$-HSD10-A $\beta$ complexes (Welch test: $\mathrm{p}=0.072$ )

WT rats $(\mathrm{p}=0.024)$. Analogously, the correlation between $17 \beta$-HSD10-cypD and 17 $\beta$-HSD10-A $\beta$ complexes was not significant in $\mathrm{Tg}$ animals $(\mathrm{R}=-0.071, \mathrm{p}=0.845)$, however, the result of Z-test indicated only borderline significance $(\mathrm{p}=0.095)$.

\section{Experiments Performed on Human CSF Samples}

Analysis of CSF samples (Table 2) revealed significant changes in levels of $\mathrm{A} \beta 1-42$ in all evaluated groups (the drops to $70.4 \%$ in MCI-others, to $53.6 \%$ in MCI-AD, to $49.5 \%$ in $\mathrm{ADD}$, and to $68.1 \%$ in FTLD) when compared to controls. Significant changes in levels of total- $\tau$ (the increases to $191.9 \%$ in MCI-AD, to $221.8 \%$ in ADD and to $174.2 \%$ in FTLD) were also observed. In levels of phospho- $\tau$, the increase to $139.2 \%$ in ADD was found compared to FTLD group. And finally, levels of $17 \beta-$ HSD10-cypD complexes were significantly decreased (the drops to $85.6 \%$ in MCI-AD, to $83.9 \%$ in ADD and to $89.9 \%$ 
Table 2 Results of CSF analysis

\begin{tabular}{lllll}
\hline Groups & $\mathrm{A} \beta 1-42(\mathrm{pg} / \mathrm{ml})$ & $\tau(\mathrm{pg} / \mathrm{ml})$ & Phospho- $\tau(\mathrm{pg} / \mathrm{ml})$ & $17 \beta-H S D 10-\mathrm{cypD}(\%)$ \\
\hline Controls & $986.3 \pm 225.3$ & $278.7 \pm 124.9$ & $50.2 \pm 23.0$ & $99.6 \pm 4.7$ \\
MCI-others & $694.5 \pm 221.7^{*}$ & $354.2 \pm 225.5$ & $52.2 \pm 26.3$ & $96.2 \pm 3.9$ \\
MCI-AD & $528.2 \pm 196.4^{* * *}$ & $534.8 \pm 355.0^{* *}$ & $76.8 \pm 52.8$ & $85.3 \pm 8.1^{* * *}$ \\
ADD & $488.1 \pm 166.7^{* * *}$ & $618.2 \pm 446.0^{* * *}$ & $71.0 \pm 35.5$ & $83.6 \pm 7.2^{* * *}$ \\
FTLD & $672.1 \pm 237.9^{* *}$ & $485.5 \pm 320.3^{*}$ & $51.0 \pm 23.3$ & $89.5 \pm 7.3 * * *$ \\
Welch test & $\mathrm{p}<0.001$ & $\mathrm{p}<0.001$ & $\mathrm{p}=0.003$ & $\mathrm{p}<0.001$ \\
\hline
\end{tabular}

Data are presented as the mean $\pm \mathrm{SD}$

CSF samples were obtained from patients of Table 1. The levels of 17 $\beta$-HSD10-cypD complexes were compared to those from the internal standards (mixed CSF samples of eight people discarded from the study) and expressed in percentage. Statistical significance (Bonferroni adjusted t-test, separate variance) was calculated with respect to controls (*Adjusted $\mathrm{p}<0.050$, **Adjusted $\mathrm{p}<0.010$, ***Adjusted $\mathrm{p}<0.001)$. The levels of phospho- $\tau$ were significantly increased in ADD patients compared to FTLD people.

in FTLD) when compared to controls (a part of the results is presented also in Fig. 6, in addition, the insert in the topright corner shows dependency of optical density on CSF volume). Positive levels of $17 \beta$-HSD10-cypD complexes were defined as values below the cut-off $(<93.0 \%)$. The sensitivity of the biomarker to ADD was $92.9 \%$ (to MCI$\mathrm{AD}$ was $86.4 \%$ and to FTLD was $73.8 \%$ ). A comparison with non-demented controls revealed the specificity of $91.7 \%$ in ADD group, however, that with FTLD only of $26.2 \%$.

Results of correlation analysis performed on data from CSF samples revealed one significant negative correlation between age and $A \beta 1-42(\mathrm{R}=-0.693, \mathrm{p}=0.012)$ and one significant positive correlation between total- $\tau$ and phospho- $\tau$ levels $(\mathrm{R}=+0.970, \mathrm{p}<0.001)$ in the control

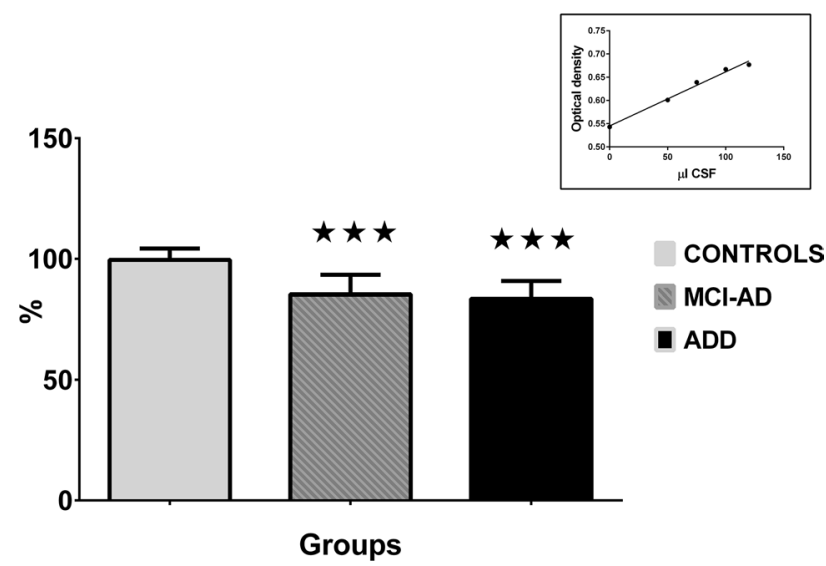

Fig. 6 Levels of 17ß-HSD10-cypD complexes in CSF of people with $\mathrm{AD}$ estimated by semi-quantitative sandwich ELISA. Data (a part of results of Table 2) are presented as the mean \pm SD. Levels of complexes were estimated in CSF samples of controls $(n=12)$, of people with mild cognitive impairment due to Alzheimer's disease (MCI$\mathrm{AD}, \mathrm{n}=44$ ) and of people with Alzheimer's disease dementia (ADD, $\mathrm{n}=56$ ). Statistical significance (Bonferroni adjusted t-test, separate variance) was calculated with respect to controls (***Adjusted $\mathrm{p}<0.001)$ group. The results of Z-test indicated a significant correlation loss in ADD (age vs A $\beta 1-42: \mathrm{R}=-0.034, \mathrm{p}=0.803$, Z-test: $\mathrm{p}=0.023 ; \tau$ vs phospho- $\tau$ : $\mathrm{R}=+0.822, \mathrm{p}<0.001$, Z-test: $\mathrm{p}=0.010$ ) and FTLD groups (age vs A $\beta$ 1-42: $\mathrm{R}$ $=-0.106, p=0.505, Z$-test: $p=0.043 ; \tau$ vs phospho- $\tau$ : $\mathrm{R}=+0.688, \mathrm{p}<0.001, \mathrm{Z}$-test: $\mathrm{p}<0.001)$ compared to the controls.

\section{Discussion}

In this work, we investigated the interaction between $17 \beta$ HSD10 and cypD in vitro using the SPR biosensor method and, for the first time, determined the kinetic parameters of this interaction. The interaction analysis revealed that $17 \beta-$ HSD10 and cypD interact with high affinity and form a stable complex (Fig. 1i-ii). This result can be supported also by co-immunoprecipitation experiment (Fig. 2, blots ii and iv). Moreover, we used ELISA to detect 17 $\beta$-HSD10-cypD complexes formed in vivo in rat brain mitochondria (Fig. 5i) and in human CSF (Table 2, Fig. 6). However, before discussing this interaction, it is worthwhile to look at the interacting biomolecules separately.

With respect to particular levels of $17 \beta-H S D 10$ and cypD, we have to note that our data obtained from quantitative ELISA did not reflect real concentrations occurring in the brain mitochondrial matrix of 11-month old WT rats since mitochondria were previously concentrated during the isolation process. However, the ratio of their size could be determined after recalculation of data to original mitochondrial fraction. Since the concentration of functional 17 $\beta$-HSD10 homotetramers was around $0.135 \mu \mathrm{M}$ (MW of human protein $=26.9 \mathrm{kDa}$ ) and that of cypD equaled $0.017 \mu \mathrm{M}$ (MW of human protein $=18.9 \mathrm{kDA}$ ), it seems that the levels of tetrameric $17 \beta$-HSD10 are more than 7 times higher in the mitochondrial matrix when compared to those of cypD. Incidentally, it is in line with the fact that $17 \beta$-HSD10 is the 
essential protein with enzymatic as well as non-enzymatic functions necessary for structural and functional integrity of mitochondria [3]. While mutational inactivation of $17 \beta$ HSD10 results in lethal phenotype [9], homozygous mice missing mitochondrial cypD survive but are more anxious and better in learning/memory tasks [22, 33]. It is important to point out that our results of correlation analysis revealed two significant negative correlations in WT rats (either between $17 \beta$-HSD10 and cypD levels or between $17 \beta$ HSD10-cypD and 17 $\beta$-HSD10-A $\beta$ complexes) which can be interpreted by a possible homeostatic interplay between levels of both mitochondrial proteins and by a potential competition for binding of cypD or $\mathrm{A} \beta$ to $17 \beta-\mathrm{HSD} 10$ in the matrix.

With respect to $\mathrm{AD}$, the strength of the study is a well chosen animal model representing the human pathology. McGill-R-Thy1-APP rat model of AD is based on expression of human $A \beta$ precursor protein carrying both the Swedish and Indiana mutations displays deficits in cognitive functions already in 3-month old rats [34] and cognitive changes are still more prominent in older animals [34-36]. Rats are characterized by intraneuronal accumulation of $A \beta$ already in 1-week old rats [34] and by extracellular $A \beta$ deposits from the age of 6 months [34,36]. Moreover, experimental results indicate that 6-month old McGill-R-Thy1-APP rats and older ones display perturbations in neuronal mitochondria [37, 38] which well agree with increased total $A \beta$ in brain mitochondrial fraction in this study (Fig. 4iii).

Our experiments performed on the rat brain mitochondrial fraction isolated from the whole left hemisphere did not reveal significant differences between $\mathrm{Tg}$ and WT rats in 17 $\beta$-HSD10 (Fig. 4i) or cypD levels (Fig. 4ii). The results do not contradict findings of marked overexpressions of both mitochondrial proteins exclusively in extremely vulnerable brain regions (as the cortex or hippocampus) of individuals with $\mathrm{AD}$ or of $\mathrm{Tg}$ rodent models of $\mathrm{AD}[2,7-9,17,22]$. On the other hand, the enhanced concentrations of 17 $\beta$-HSD10 in CSF of individuals with AD [10-12] suggest that the moderate average increase in 17 $\beta$-HSDS10 expression in the brains of Tg models of AD should be expected. We assume that up-regulation and overexpression of $17 \beta$-HSD10 in the extremely vulnerable brain regions of McGill-R-Thy1APP rats is very probable but its reduced level in the mitochondrial matrix may be due to another mechanism. E.g., it has been demonstrated that $\mathrm{A} \beta$ accumulated in both outer and inner mitochondrial membranes can block transports of nucleus-encoded mitochondrial proteins [39]. It seems therefore that A $\beta$-related blocking of Pink1-mediated Parkin pathway could also partly eliminate levels of originally up-regulated 17 $\beta$-HSD10 (and perhaps also these of cypD) in the mitochondrial matrix. Our experiments support it via increased levels of mitochondrial $\mathrm{A} \beta$ (Fig. 4iii, note that it is not possible to distinguish between mitochondrial membrane-bound $A \beta$ and free/bound $A \beta$ in the matrix in our experiments) and perhaps also via missing significant changes in 17 $\beta$-HSD10-A $\beta$ complexes (Fig. 5ii). However, although the alterations are not significant here, a trend to the increase of $17 \beta$-HSD10-A $\beta$ complexes is evident (see also the borderline significance value).

On the other hand, despite of unchanged levels of $17 \beta-$ HSD10 (Fig. 4i) and cypD (Fig. 4ii) in mitochondria of McGill-R-Thy 1-APP rats, $17 \beta$-HSD10-cypD complexes were significantly decreased (Fig. 5i). In addition, we observed the significant loss of negative correlation between 17 $\beta$-HSD10 and cypD levels or the similar change with borderline significance in correlations between $17 \beta$ HSD10-cypD and 17 $\beta$-HSD10-A $\beta$ complexes (Results). The result obtained on Tg animal model of AD can be also supported by our results on human CSF samples from AD patients (Table 2, Fig. 6). This can be interpreted via A $\beta$-related dysbalance in levels of mitochondrial $17 \beta$ HSD10 and cypD and via trend to dysbalance among various complexes of $17 \beta$-HSD 10 which can finally lead to the weakened function of $17 \beta$-HSD10 to regulate cypD in the matrix, in accordance with literature [20]. It seems that especially some fragments of accumulated $A \beta$ via its enhanced binding to $17 \beta$-HSD10 could eliminate the interaction of $17 \beta$-HSD10 and cypD [40] and thus decrease the levels of 17/-HSD10-cypD complexes in the matrix. Free cypD could consequently translocate to the inner mitochondrial membrane and open MPTP. It is well known that MPTP opening results in inner membrane potential collapse, respiratory chain uncoupling, halt of mitochondrial adenosine triphosphate synthesis, and eventually mitochondrial swelling, rupture, and cell death [20]. We thus suggest that the weakened function of $17 \beta$-HSD10 to regulate cypD in the mitochondrial matrix can be directly involved in mitochondrial dysfunction.

Incidentally, although levels of $17 \beta-\mathrm{HSD} 10-\mathrm{A} \beta$ complexes are not significantly increased in mitochondria of McGill-R-Thy1-APP rats (Fig. 5ii), the balance between $17 \beta-H S D 10-c y p D$ and $17 \beta-H S D 10-A \beta$ complexes seems to be moderately deflected in $\mathrm{AD}$ after all towards $17 \beta$-HSD10 bounded to $A \beta$. Our new results of SPR biosensor indicate that dual $17 \beta$-HSD10-cypD and $17 \beta-$ HSD10-A $\beta$ as well as tertial $17 \beta-\mathrm{HSD} 10-\mathrm{A} \beta-\mathrm{cypD}$ complexes can be created in vitro and that there are pronounced effects of ionic composition $/ \mathrm{pH}$ and particular $\mathrm{A} \beta$ fragments on the interaction of $17 \beta-H S D 10$ and cypD [40]. We suppose that missing significant changes in $17 \beta$-HSD10-A $\beta$ complexes in mitochondria of McGill-R-Thy 1-APP rats may be based not only on unchanged 17 $\beta$-HSD10 but also on the above-mentioned tertial complexes probably undetected by our sandwich ELISA.

And finally, our results revealed that CSF levels of $17 \beta$ HSD10-cypD complexes can be a very sensitive biomarker of $\mathrm{AD}$ including early disease stages (compare the very high 
sensitivity to MCI-AD $86.4 \%$ with that to ADD 92.9\%). However, its specificity to AD pathology remains questionable when taking into account the similar results in FTLD patients. It seems that CSF levels of $17 \beta$-HSD10-cypD complexes reflect mitochondrial dysfunction in agreement with previous findings of mitochondrial dysfunction as a common feature of neurodegeneration [41]. On the other hand, 17 $\beta$-HSD10-cypD complexes in CSF, similarly as $\mathrm{A} \beta-\tau$ complexes evaluated in our older study [42], do not reflect degree of cognitive impairment (we did not observe significant correlations with MMSE in ADD $(\mathrm{R}=-0.035$, $\mathrm{p}=0.801)$ as well as in FTLD $(\mathrm{R}=+0.098, \mathrm{p}=0.536)$ in this study). Taken together, the advantages of this new biomarker (its high sensitivity to early as well as later stages of AD) are not greater than the disadvantages (its less specificity, the levels do not markedly reflect disease progression or degree of cognitive impairment) and thus we do not recommend it as the new biomarker of AD.

\section{Conclusions}

In this work, we used the SPR biosensor method to observe in vitro interaction of the two nucleus-encoded mitochondrial proteins, 17 $\beta$-HSD10 and cypD, and, for the first time, determined kinetic parameters of the interaction. The interaction analysis revealed that the two proteins exhibit high affinity towards each other and form a stable complex. In brain mitochondria isolated from Tg animal model of AD (McGill-R-Thy1-APP rats) and in CSF samples of AD patients, we observed the significant drops in levels of $17 \beta$ HSD10-cypD complexes which could indicate the weakened function of $17 \beta$-HSD10 to regulate cypD in the mitochondrial matrix. CSF levels of 17 $\beta$-HSD10-cypD complexes seem to be the very sensitive indicator of mitochondrial dysfunction observed in neurodegeneration but unfortunately not specific to AD pathology. We do not recommend it as the new biomarker of AD.

Acknowledgement The study was supported by AZV CR (16-27611A) project. The authors thank Jan Plicka (Elisa Development s.r.o., Czech Republic) for help in coating plates by $\operatorname{IgG}$ and by the capture antibody.

Open Access This article is licensed under a Creative Commons Attribution 4.0 International License, which permits use, sharing, adaptation, distribution and reproduction in any medium or format, as long as you give appropriate credit to the original author(s) and the source, provide a link to the Creative Commons licence, and indicate if changes were made. The images or other third party material in this article are included in the article's Creative Commons licence, unless indicated otherwise in a credit line to the material. If material is not included in the article's Creative Commons licence and your intended use is not permitted by statutory regulation or exceeds the permitted use, you will need to obtain permission directly from the copyright holder. To view a copy of this licence, visit http://creativecommons.org/licenses/by/4.0/.

\section{References}

1. Yang SY, He XY, Schulz H (2005) Multiple functions of type 10 17 $\beta$-hydroxysteroid dehydrogenase. Trends Endocrin Met 16:167-175

2. Yang SY, He XY, Isaacs C, Dobkin C, Miller D, Philipp M (2014) Roles of $17 \beta$-hydroxysteroid dehydrogenase type 10 in neurodegenerative disorders. J Steroid Biochem Mol Biol 143:460-472

3. Rauschenberger K, Schöler K, Sass JO, Sauer S, Djuric Z, Rumig C, Wolf NI, Okun JG, Kolker S, Schwarz H, Fisher C, Grziwa B, Runz H, Numann A, Shafqat N, Kavanagh KL, Hammerling G, Wanders RJA, Shield JPH, Wendel U, Stern D, Nawroth P, Hoffmann GF, Bartram CR, Arnold B, Bierhaus A, Oppermann U, Steinbeisser H, Zschocke J (2010) A non-enzymatic function of 17 $\beta$-hydroxysteroid dehydrogenase type 10 is required for mitochondrial integrity and cell survival. EMBO Mol Med 2:51-62

4. Harbauer AB, Zahedi RP, Sickman A, Pfanner N, Meisinger C (2014) The protein import machinery of mitochondria-a regulatory hub in metabolism, stress, and disease. Cell Metab 19:357-372

5. Bertolin G, Jacoupy M, Traver S, Ferrendo-Miguel R, Saint Georges T, Grenier K, Ardila-Osorio H, Muriel MP, Takahashi H, Lees AJ, Gautier C, Guedin D, Coge F, Fon EA, Brice A, Corti O (2015) Parkin maintains mitochondrial levels of the protective Parkinson's disease-related enzyme 17- $\beta$ hydroxysteroid dehydrogenase type 10. Cell Death Differ 22:1563-1576

6. Von Stockum S, Nardin A, Schrepfer E, Ziviani E (2016) Mitochondrial dynamics and mitophagy in Parkinson's disease: a fly point of view. Neurobiol Dis 90:58-67

7. Yan SD, Stern DM (2005) Mitochondrial dysfunction and Alzheimer's disease: role of amyloid- $\beta$ peptide alcohol dehydrogenase (ABAD). Int J Exp Path 86:161-171

8. Yan SD, Fu J, Soto C, Chen X, Zhu H, Al-Mohanna F, Collison K, Zhu A, Stern E, Saido T, Tohyama M, Ogawa S, Roher A, Stern D (1997) An intracellular protein that binds amyloid-beta peptide and mediates neurotoxicity in Alzheimer's disease. Nature 389:689-695

9. Lustbader JW, Cirilli M, Lin C, Xu HW, Takuma K, Wang N, Casperson C, Chen X, Pollak S, Chaney M, Trinchese F, Liu S, Gunn-Moore F, Lue LF, Walker DG, Kuppusamy P, Zewier Z, Arancio O, Stern D (2004) ABAD directly links A $\beta$ to mitochondrial toxicity in Alzheimer's disease. Science 304:448-452

10. Kristofikova Z, Bockova M, Hegnerova K, Bartos A, Klaschka J, Ricny J. Ripova D, Homola J (2009) Enhanced levels of mitochondrial enzyme $17 \beta$-hydroxysteroid dehydrogenase type 10 in patients with Alzheimer disease and multiple sclerosis. Mol Biosyst 5:1174-1179

11. Kristofikova Z, Ripova D, Bartos A, Bockova M, Hegnerova K, Ricny J, Cechova L, Vrajov M, Homola J (2013) Neuroinflammation and complexes of $17 \beta$-hydroxysteroid dehydrogenase type 10 - amyloid $\beta$ in Alzheimer's disease. Curr Alzheimer Res 10:165-173

12. Kristofikova Z, Ricny J, Vyhnalek M, Hort J, Laczo J, Sirova J, Klaschka J, Ripova D (2015) Levels of $17 \beta$-hydroxysteroid dehydrogenase type 10 in cerebrospinal fluid of people with mild cognitive impairment and various types of dementias. J Alzheimers Dis 48:105-114

13. Oppermann UCD, Salim S, Tjernberg LO, Terenius L, Jörnvall H (1999) Binding of amyloid $\beta$-peptide to mitochondrial hydroxyacyl-CoA dehydrogenase (ERAB): regulation of an SDR enzyme acitivity with implications for apoptosis in Alzheimer's disease. FEBS Lett 451:238-242

14. Powell AJ, Read JA, Banfield MJ, Gunn-Moore F, Yan SD, Lusbader J, Stern AR, Stern DM, Brady RL (2000) Recognition of structurally diverse substrates by type II 3-hydroxyacyl-CoA 
dehydrogenase (HADH II)/amyloid- $\beta$ binding alcohol dehydrogenase (ABAD). J Mol Biol 303:311-327

15. Yan Y, Liu Y, Sorci M, Belfort G, Lustbader JW, Yan SD, Wang C (2007) Surface plasmon resonance and nuclear magnetic resonance studies of $\mathrm{ABAD}-\mathrm{A} \beta$ interactions. Biochemistry 46:1724-1731

16. Hegnerova K, Bockova M, Vaisocherova H, Kristofikova Z, Ricny J, Ripova D, Homola J (2009) Surface plasmon resonance biosensors for detection of Alzheimer disease biomarker. Sens Actuator B Chem 139:69-73

17. Chen JX, Yan SD (2010) Role of mitochondrial amyloid- $\beta$ in Alzheimer's disease. J Alzheimers Dis 20:S569-S578

18. Muirhead KEA, Borger E, Aitken L, Conway SJ, Gunn-Moore FJ (2010) The consequences of mitochondrial amyloid $\beta$-peptide in Alzheimer's disease. Biochem J 426:255-270

19. Yao J, Du H, Yan S, Fang F, Wang C, Lue LF, Guo L, Chen D, Stern DM, Gunn-Moore FJ, Chen JX, Arancio O, Yan SD (2011) Inhibition of amyloid- $\beta$ (A $\beta$ ) peptide-binding alcohol dehydrogenase- $A \beta$ interaction reduces $A \beta$ accumulation and improves mitochondrial function in a mouse model of Alzheimer's disease. J Neurosci 31:2313-2320

20. Carlson EA, Marquez RT, Du F, Wang Y, Xu L, Yan SD (2015) Overexpression of $17 \beta$-hydroxysteroid dehydrogenase type 10 increases pheochromocytoma cell growth and resistance to cell death. BMC Cancer 15:166. https://doi.org/10.1186/s1288 5-015-1173-5

21. Du H, Yan SD (2010) Mitochondrial permeability transition pore in Alzheimer's disease: cyclophilin D and amyloid beta. Biochim Biophys Acta 1802:198-204

22. Du H, Guo L, Zhang W, Rydzewska M, Yan SD (2011) Cyclophilin D deficiency improves mitochodnrial function and learning/memory in aging Alzheimer disease mouse model. Neurobiol Aging 32:398-406

23. Springer T, Piliarik M, Homola J (2010) Surface plasmon resonance sensor with dispersionless microfluidics for direct detection of nucleic acids at the low femtomole level. Sensor Actuat B Chem 145:588-591

24. Springer T, Piliarik M, Homola J (2010) Real-time monitoring of biomolecular interactions in blood plasma using a surface plasmon resonance biosensor. Anal Bioanal Chem 398:1955-1961

25. Springer T, Homola J (2012) Biofunctionalized gold nanoparticles for SPR-biosensor-based detection of CEA in blood plasma. Anal Bioanal Chem 404:2869-2875

26. Kissinger CR, Rejto PA, Pelletier LA, Thomson JA, Showalter RE, Abre MA, Agree CS, Margosiak S, Meng JJ, Aust TM, Vanderpool D, Li B, Tempczyk-Russell A, Villafranca JE (2004) Crystal structure of human ABAD/HSD10 with a bound inhibitor: implications for design of Alzheimer's disease therapeutics. J Mol Biol 342:943-952

27. Rajapakse N, Shimizu K, Payne M, Busija D (2001) Isolation and characterization of intact mitochondria from neonatal rat brain. Brain Res Protoc 8:176-183

28. Bradford MM (1976) A rapid and sensitive method for the quantitation of microgram quantities of protein utilizing the principle of protein-dye binding. Anal Biochem 72:248-254

29. Albert MS, DeKosky ST, Dickson D, Dubois B, Feldman HH, Fox NC, Gamst A, Holtzman DM, Jagust WJ, Petersen RC, Snyder PJ, Carrillo MC, Thies B, Phelps CH (2011) The diagnosis of mild cognitive impairment due to Alzheimer's disease: recommendations from the National Institute on Aging-Alzheimer's Association workgroups on diagnostic guidelines for Alzheimer's diseases. Alzheimers Dement 7:270-279

30. McKhann GM, Knopman DS, Chertkow H, Hyman BT, Jack CR, Kawas CH, Klunk WE, Koroshetz WJ, Manly JJ, Mayeux R, Mohs RC, Morris JC, Rossor MN, Scheltens P, Carrillo MC, Thies
B, Weintraub S, Phelps CH (2011) The diagnosis of dementia due to Alzheimer's disease: recommendations from the National Institute on Aging-Alzheimer's Association workgroups on diagnostic guidelines for Alzheimer's disease. Alzheimers Dement 7:263-269

31. Neary D, Snowden JS, Gustafson L, Passant U, Stuss D, Black S, Freedman M, Kertesz A, Robert PH, Albert M, Boone K, Miller BL, Cummings J, Benson DF (1998) Frontotemporal lobar degeneration: a consensus on clinical diagnostic criteria. Neurology 51:1546-1554

32. Sheskin DJ (2011) Measures of association/correlation. In: Sheskin DJ (ed) Handbook of parametric and nonparametric statistical procedures. Chapman and Hall/CRC, New York, pp 1219-1413

33. Luvisetto S, Basso E, Petronilli V, Bernardi P, Forte M (2008) Enhancement of anxiety, facilitation of avoidance behavior, and occurrence of adult-onset obesity in mice lacking mitochondrial cyclophilin D. Neuroscience 155:585-596

34. Leon WC, Canneva F, Partridge V, Allard S, Ferretti MT, DeWilde A, Vercauteren F, Atifeh R, Ducatenzeiler A, Klein W, Szyf M, Alhonen L, Cuello AC (2010) A novel transgenic rat model with a full Alzheimer's-like amyloid pathology displays pre-plaque intracellular amyloid-beta-associated cognitive impairment. J Alzheimers Dis 20:113-126

35. Petrasek T, Vojtechova I, Lobellova V, Popelikova A, Janikova M, Brozka H, Houdek P, Sladek M, Sumova A, Kristofikova Z, Vales K, Stuchlik A (2018) The McGill transgenic rat model of Alzheimer's disease displays cognitive and motor impairments, changes in anxiety and social behavior, and altered circadian activity. Front Aging Neurosci 10:250. https://doi.org/10.3389/fnagi.2018.00250

36. Iulita MF, Allard S, Richter L, Munter LM, Ducatenzeiler A, Weise C, Do Carmo S, Klein WL, Multhaup G, Cuello AC (2014) Intracellular $A \beta$ pathology and early cognitive impairments in a transgenic rat overexpressing human amyloid precursor protein: a multidimensional study. Acta Neuropathol Commum 2:61. https ://doi.org/10.1186/2051-5960-2-61

37. Nilsen LH, Witter MP, Sonnewald U (2014) Neuronal and astrocytic metabolism in a transgenic rat model of Alzheimer's disease. J Cereb Blood Flow Metab 34:906-914

38. Martino Adami PV, Quijano C, Magnani N, Galeano P, Evelson P, Cassina A, Do Carmo S, Leal MC, Castano EM, Cuello AC, Morelli L (2017) Synaptosomal bioenergetic defects are associated with cognitive impairment in a transgenic rat model of early Alzheimer's disease. J Cereb Blood Flow Metab 37:69-84

39. Reddy PH, Beal F (2008) Amyloid beta, mitochondrial dysfunction and synaptic damage: implications for cognitive decline in aging and Alzheimer's disease. Trends Mol Med 14:45-53

40. Hemmerova E, Springer T, Kristofikova Z, Homola J (2019) In vitro study of interaction of $17 \beta$-hydroxysteroid dehydrogenase type 10 and cyclophilin D and its potential implications for Alzheimer's disease. Sci Rep 9:16700. https://doi.org/10.1038/s4159 8-019-53157-7

41. Rossi L, Lombardo MF, Ciriolo MR, Rotilio G (2004) Mitochondrial dysfunction in neurodegenerative diseases associated with copper imbalance. Neurochem Res 29:493-504

42. Kristofikova Z, Ricny J, Kolarova M, Vyhnalek M, Hort J, Lacso J, Sirova J, Ripova D (2014) Interactions between amyloid $\beta$ and tau in cerebrospinal fluid of people with mild cognitive impairment and Alzheimer's disease. J Alzheimers Dis 42(3):S91-S98

Publisher's Note Springer Nature remains neutral with regard to jurisdictional claims in published maps and institutional affiliations. 